\title{
Analysis of Performance and Emission Parameters on Diesel Engine Using Various Blended Bio-Fuels
}

\author{
K. Praveen Kumar ${ }^{1}$, K. Yuvaraj, M.E ${ }^{2}$ \\ ${ }^{1}$ M. E (Thermal Engineering), II year, Department of Mechanical Engineering, Excel Engineering College, Namakkal \\ ${ }^{2}$ Assistant Professor, Department of Mechanical Engineering, Excel Engineering College, Namakkal
}

\begin{abstract}
Bio-fuels are proved to be very good substitutes for the existing petroleum fuels. Biodiesel can be extracted from vegetable oils and waste fats. Trans-esterification is simply described as the chemical breaking of oil using alcohol to form alcohol esters and glycerol. This procedure involves a three step process, acid, alkaline esterification and washing based on FFA content. Then methyl esters of fuel (Soybean Oil, Rapeseed Oil, Tamanu Oil, and Corn Oil) have been blended with diesel fuel in various proportions to check the properties for theoretical investigation. The scope of the technology is to provide utility and comfort with no damage to the user or to the surroundings. In this study, the performance and emissions of single cylinder, four stroke, diesel engine operating on diesel and biodiesels have been investigated theoretically using the simulation software Diesel-RK and experimentally in a IC Engine. As a result, the blends B3O SME and B30 Tamanu oil methyl ester have shown a better performance. All blends show reduction in HC, NOx with increase in load. This is due to higher cetane number, calorific value and oxygen content. But, CO has slightly increased than the diesel fuel at all load condition. From Experimental investigations, blending of Tamanu oil methyl esters up to $30 \%$ with diesel fuel can be used without any hardware modification in diesel engine and it reduces the harmful emissions.
\end{abstract}

Keywords: Diesel Engine, Biodiesel, DIESEL-RK, Theoretical Modelling, IC Engine Performance, Emissions, Trans-esterification, Soybean Oil, Tamanu Oil, Corn Oil, Rapeseed Oil

\section{Introduction}

Depleting mineral oil reserves and increasing cost of the petroleum products demands an intensive search for new alternative fuels. In recent years, there has been a considerable effort to develop and introduce alternative renewable fuels to replace conventional petroleum-based fuels.

\begin{abstract}
A. Biodiesel as an Alternate Substitute for Diesel
Biodiesel refers to a vegetable oil or animal fat-based diesel fuel consisting of long-chain alkyl (methyl, propyl or ethyl)esters. Biodiesel is typically made by chemically reacting lipids (e.g., vegetable oil, animal fat) with an alcohol producing fatty acid esters and is meant to be used in standard diesel engines alone, or blended with diesel [3]. The esters of vegetable oils are popularly known as biodiesel. It is the process of reacting triglyceride with an alcohol in presence of a catalyst to produce glycerol and fatty acid esters. In India, attempts are being made for using non-edible and under-exploited oils for production of esters.
\end{abstract}

\section{Extraction Of Biodiesel}

Oil from dried and peeled Tamanu seed is extracted by an engine driven screw press. However, it must be noted that oil extracted by mechanical presses needs further treatment of filtering process and degumming.

\section{A. Experimental Setup for Biodiesel Production}

The setup shown in figure 1 is used in the acid and alkali esterification process consists of two necked round bottom flask to carry out the reaction, a magnetic stirrer with heater for continuous heating and stirring, water cooled condenser to restrict the evaporation of methanol during the heating process carried out in the two necked round bottom flask [4]. The two necked round bottom flask is partially immersed in to the bowl containing water in order to constantly distribute the heat. External water supply is provided for condenser to continuously cool the evaporated methanol from oil [4].

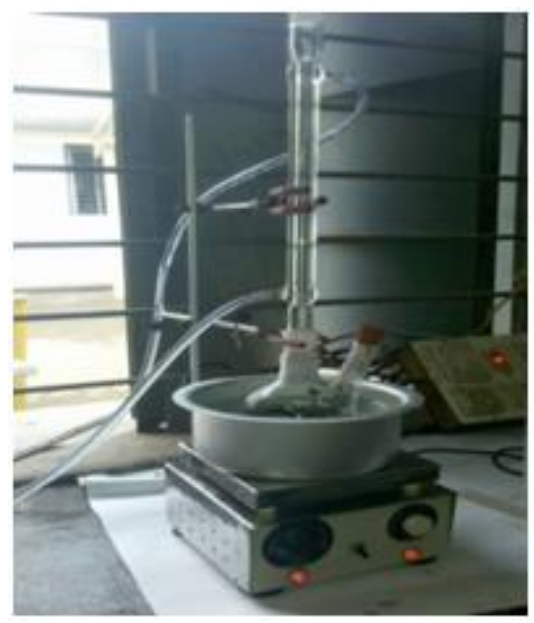

Figure 1: Trans-esterification Setup

\section{B. Trans-esterification}

Trans-esterification of a triglyceride typically consists of a series of consecutive reversible reactions. The triglyceride is converted stepwise into a diglyceride, a glyceride and finally a glycerol, with the removal of an alkyl in each step. The free fatty acid content is $19.6 \%$ by Gas Chromatography test [6]. Trans-esterification can do in two ways, either one step method or two step methods based on the FFA content [6]. 


\section{International Journal of Science and Research (IJSR)}

ISSN (Online): 2319-7064

Index Copernicus Value (2013): 6.14 | Impact Factor (2015): 6.391

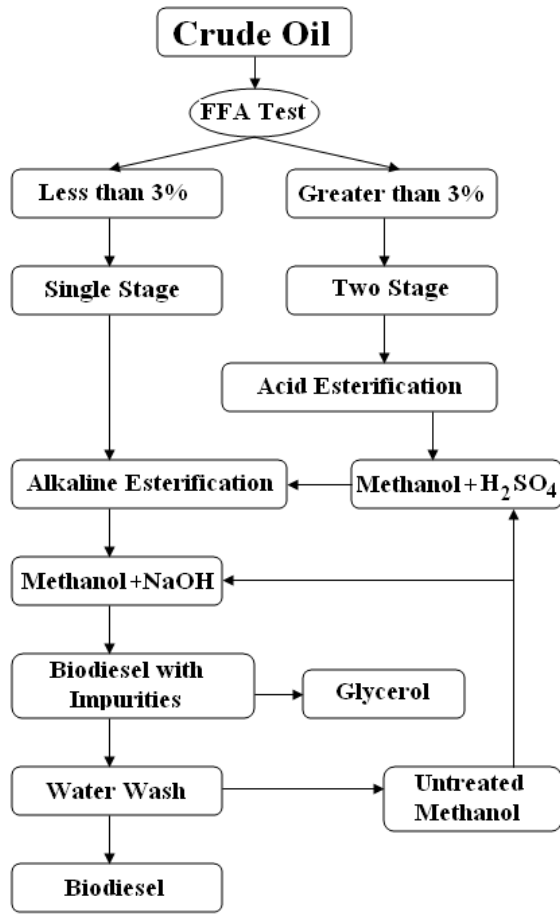

Figure 2: Trans-esterification Chart

\section{Two Step Method}

Since the percentage of FFA is more than $3 \%$, the Transesterification process is by two step method [6]. The high percentage of FFA content makes difficulties in the alkaline Trans-esterification process due to soap formation. Therefore, two stages of procedure are adopted here. High FFA oil was converted to triglycerides in acid esterification process with methanol using anhydrous $\mathrm{H}_{2} \mathrm{SO}_{4}$ (acid catalyst). The oil is heated at 50o-55。C in a standard flask [6]. Methanol in the required quantity is taken and measured quantity of anhydrous $\mathrm{H}_{2} \mathrm{SO}_{4}$ is dissolved in it. The mixture is continuously stirred at constant speed and $60_{\circ} \mathrm{C}$ for 2 hours to avoid methanol loss [1]. On settling, the excess methanol forms as the top layer and diglyceride remain as the bottom layer. The top layer is removed and diglyceride is collected. The bottom layer is used for the Alkaline Transesterification.

At second level, the separated oil from the separating funnel has to undergo Trans-esterification. Methoxide (methanol + sodium hydroxide) is added with the obtained ester and heated to $60^{\circ} \mathrm{C}$ for 1 hour with continuous stirring [1]. After the reaction, the glycerol is separated from the methyl esters.

\section{Water Wash}

The upper layer of alkali Trans-esterification product is removed and treated for the water wash to remove the impurities (like traces of glycerol, unused methanol, soap particles, etc.) from the biodiesel.

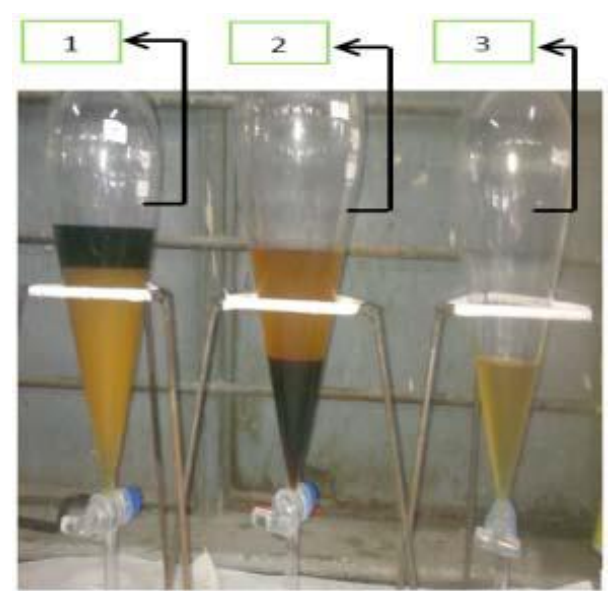

Figure 3: Trans-esterification Process

- Alkaline Esterification

- Acid Esterification

- Water Wash

\section{Characterization of Tamanu Oil and its Blends with Diesel}

A bomb calorimeter is used to measure the calorific value of various test fuels. Calorific values are $44500 \mathrm{KJ} / \mathrm{Kg}$ for diesel and $41450 \mathrm{KJ} / \mathrm{Kg}$ for Tamanu oil [8]. The kinematic viscosities of the different blends of tamanu oil and diesel fuels were determined by using a Redwood viscometer at room temperature. Pensky Marten's flash point apparatus was used to the determine flash and fire points.

Table 1: Yield obtained

\begin{tabular}{|c|c|}
\hline Dried Fruit & $2.5 \mathrm{Kg}$ \\
\hline Crude Oil Obtained & $1.25 \mathrm{Litres}$ \\
\hline Methanol added & 0.8 Litres \\
\hline Biodiesel Obtained & 1 Litres \\
\hline Glycerol & 0.2 Litres \\
\hline Yield & $80 \%$ Approx. \\
\hline
\end{tabular}

Table 2: Properties of Diesel and Tamanu oil

\begin{tabular}{|c|c|c|c|c|}
\hline Properties & $\begin{array}{c}\text { Flash Point } \\
\left({ }^{\circ} \mathrm{C}\right)\end{array}$ & $\begin{array}{c}\text { Fire Point } \\
\left({ }^{\circ} \mathrm{C}\right)\end{array}$ & $\begin{array}{c}\text { Density } \\
\left(\mathrm{kg} / \mathrm{m}^{3}\right)\end{array}$ & $\begin{array}{c}\text { Kinematic } \\
\text { Viscosity }(\mathrm{cSt})\end{array}$ \\
\hline Diesel & 65 & 84 & 0.86 & 3.06 \\
\hline Tamanu Oil & 146 & 160 & 0.905 & 4.21 \\
\hline B10 & 72 & 96 & 0.865 & 3.12 \\
\hline B20 & 80 & 104 & 0.868 & 3.34 \\
\hline B30 & 86 & 118 & 0.873 & 3.57 \\
\hline B40 & 95 & 130 & 0.877 & 3.76 \\
\hline
\end{tabular}

\section{Experimental Setup For Testing Biofuel On Engine}

Using esterified Tamanu oil in the compression ignition diesel engine at a rated speed of 1,500 rpm, the performance analysis is carried out. In every test, volumetric efficiency specific fuel consumption, air flow rate and cooling water temperature are measured with instrumentation provided on the engine. 


\section{International Journal of Science and Research (IJSR) \\ ISSN (Online): 2319-7064}

Index Copernicus Value (2013): 6.14 | Impact Factor (2015): 6.391

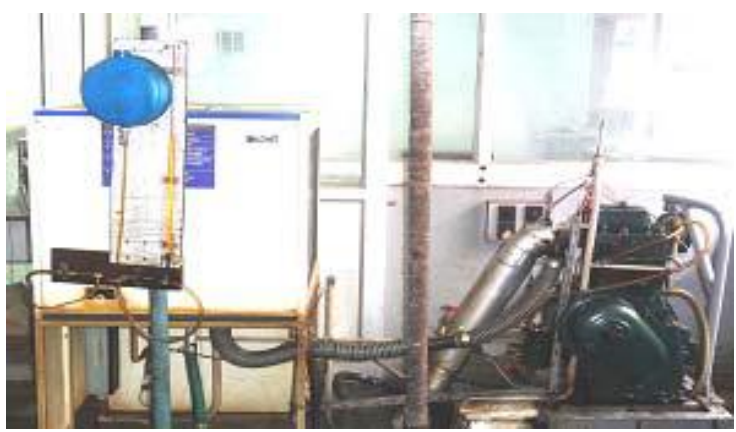

Figure 4: Engine Setup

The performance characteristics, combustion characteristics, and exhaust emission levels are performed at various operating conditions. The performance parameters were calculated from the fundamental relations between these measurements while varying the load on the engine from $0 \%$ to $100 \%$ in approximate steps of $25 \%$. Cylinder, four stroke diesel, water cooled, power $5.2 \mathrm{~kW}$ at $1500 \mathrm{rpm}$, stroke 110 $\mathrm{mm}$, bore $87.5 \mathrm{~mm}, 661 \mathrm{cc}$, and compression ratio of 17.5. It is coupled with Mechanical loading type. The test rig is provided with Piezo sensor to measure pressure of the engine cylinder online and the same procedure is repeated for other loads.

\section{Performance Characteristic Curves}

Performance curves have been drawn for various parameters like $\prod_{\mathrm{bt}}, \prod_{\text {mech, }}$ SFC, etc. as mentioned above. For the convenience of easy understanding biodiesel with diesel (Diesel, B10, B20, B30, and B40) have noted in all charts.

\section{A. Brake Thermal Efficiency}

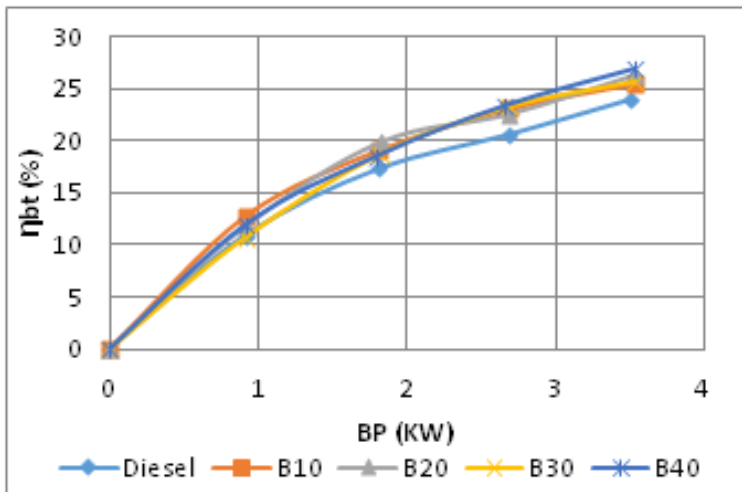

Figure 5: Brake Power Vs Brake Thermal Efficiency

Brake Thermal Efficiency is defined as brake power of a heat engine as a function of the thermal input from the fuel. It is observed from Figure 5, BTE of all blends are constantly increases based on the load condition and B40 have higher brake thermal efficiency.

\section{B. Mechanical Efficiency}

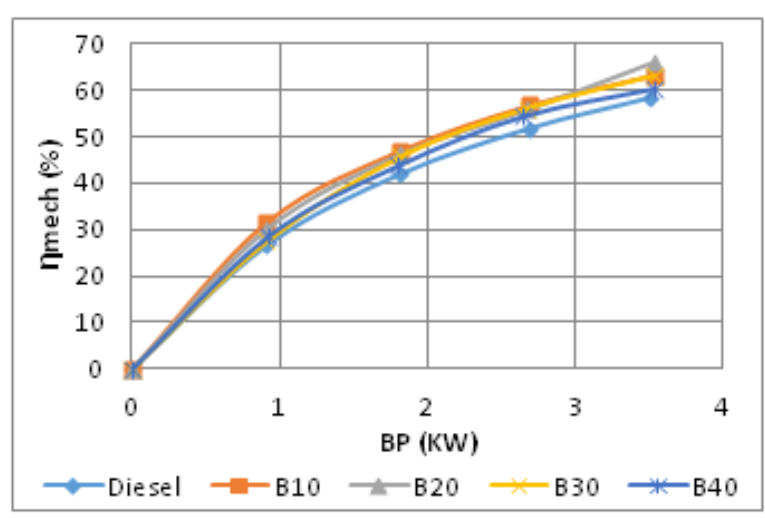

Figure 6: Brake Power Vs Mechanical Efficiency

Figure 6 shows that B10 have higher efficiency at various loads but at the full load condition B20 has the higher efficiency than the B10. Diesel fuel has little bit lag in the mechanical efficiency compared with that Biodiesel blends. This shows that the biodiesel lubricity have reduces the friction losses.

\section{Specific Fuel Consumption (Sfc)}

Among the blend B10 is lowest at all loads which is normally the optimum for any diesel engine. Hence SFC point of view B10 may be advantages. This is because of the combined effects of higher heating value and the lower fuel flow rate due to high density of the blends. Higher proportions of tamanu oil in the blends increases the viscosity which in turn increased the specific fuel consumption due to poor atomization of fuel.

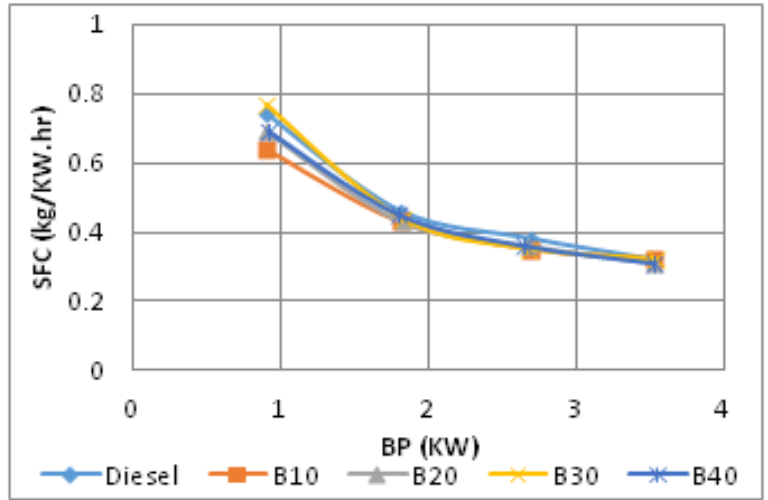

Figure 7: Brake Power Vs Specific Fuel Consumption

\section{Fuel Consumption}

It is observed from the Figure 8, Fuel consumption has increased in all load condition for diesel fuel. Among all other blends, B10 has the lower Fuel consumption rate. This is due to presence of oxygen content and the viscosity in the biodiesel. So, when the fuel blend ratio increases, viscosity of fuel also increases simultaneously. 


\section{International Journal of Science and Research (IJSR) \\ ISSN (Online): 2319-7064}

Index Copernicus Value (2013): 6.14 | Impact Factor (2015): 6.391

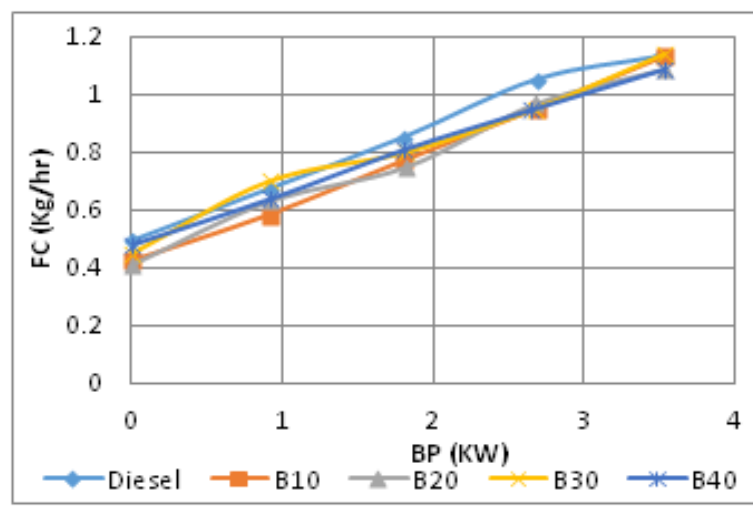

Figure 8: Brake Power Vs Fuel Consumption

\section{Flue Gas Analyzer Kid}

The schematic diagram for flue gas analyzer is drawn below Figure 9, the Gas analyzer kid consists of probe, hand set remote connection, and analyzer. While running the Diesel Engine, with the help of an analyzer kid the emissions such as carbon monoxide (CO), hydrocarbon ( $\mathrm{HC})$, nitrogen oxides $\left(\mathrm{NO}_{\mathrm{x}}\right)$, carbon dioxide $\left(\mathrm{CO}_{2}\right)$, and oxygen $\left(\mathrm{O}_{2}\right)$ for Biodiesel blends and Diesel fuel can be measured.

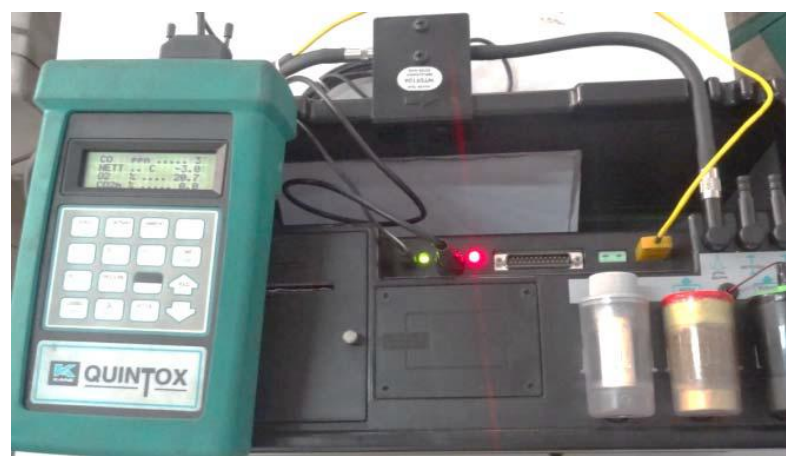

Figure 9: Flue Gas Analyzer

\section{Emission Characteristic Charts}

Emission characteristics charts have been drawn using the values obtained from emission test. The variation in the volume of emissions such as $\mathrm{CO}, \mathrm{NOx}$ and $\mathrm{HC}$ is shown for the various loads using the emission characteristic curves.

\section{A. Carbon Monoxide Emission}

From the Figure 10, Lower $\mathrm{CO}$ emission in the blends is probably due to higher oxygen availability in the fuel. B10, B20 has lower CO emissions when compared with petroleum diesel at full load. However, the results with higher blends are different with higher $\mathrm{CO}$ emissions at higher loads. Higher viscosity, improper spray pattern with higher blend percentage resulting in incomplete combustion may have increased the $\mathrm{CO}$ emissions.

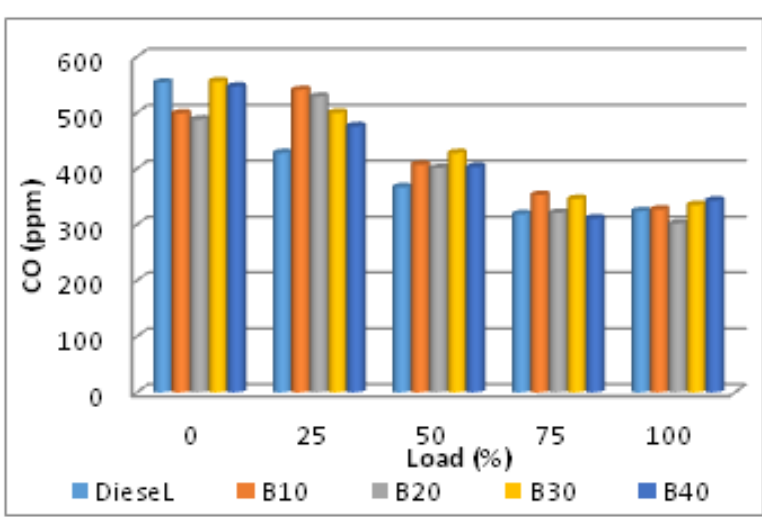

Figure 10: Load Vs Carbon Monoxide

\section{B. $\mathrm{CO}_{2}$ Emission}

Figure 11, shows the emission levels of $\mathrm{CO}_{2}$ for various blends and diesel. The test measurement reveals that the $\mathrm{CO}_{2}$ emission for all blends expect B40 are less as compared to diesel at all loads. The rising trend of $\mathrm{CO}_{2}$ emission with load is due to the higher fuel entry as the load increases. Biofuels contain lower carbon content as compared to diesel and hence the $\mathrm{CO}_{2}$ emission is comparatively lower.

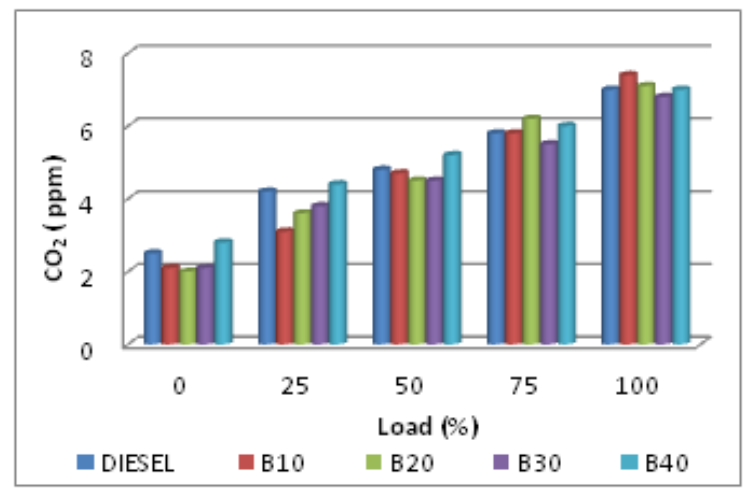

Figure 11: Load Vs Carbon Dioxide

\section{Unburnt Hydrocarbons}

Decreased Unburnt Hydrocarbon emissions clearly show that the combustion in the engine takes homogeneously. From Figure 12, it is very clear that increasing the blend percentage of tamanu oil decreases the UBHC emissions. All blends have shown lower UBHC emissions after about $75 \%$ load. This may be due to higher oxygen content as well as the higher cetane number. Physical properties of fuels such as density and viscosity influence the hydrocarbon emissions. Among the blends, B30 has lower UBHC emissions.

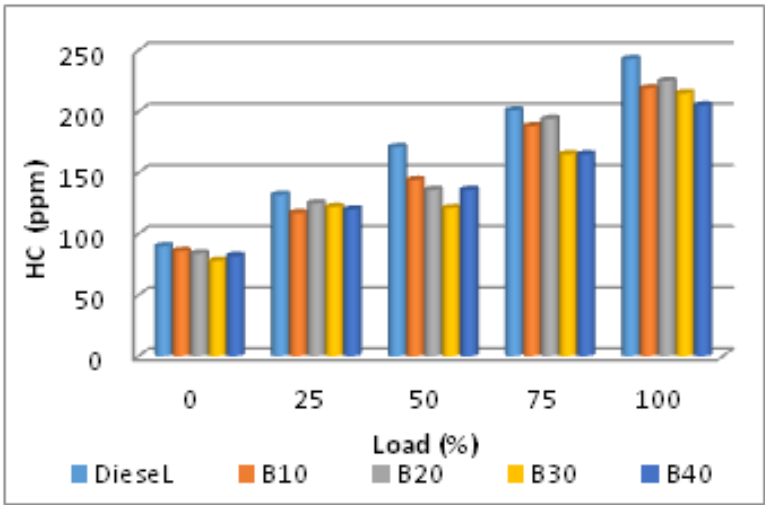

Figure 12: Load Vs Hydrocarbon

\section{Volume 5 Issue 6, June 2016 www.ijsr.net}




\section{International Journal of Science and Research (IJSR) \\ ISSN (Online): 2319-7064 \\ Index Copernicus Value (2013): 6.14 | Impact Factor (2015): 6.391}

\section{NOx Emission}

From the Figure 13, NOx emissions for all blends are less as compared to diesel at all loads. This is probably due to lower combustion temperature in the engine cylinder with increasing load and blends. It is also observed that with increasing the percentage tamanu blends there is a trend of decreasing NOx emissions.

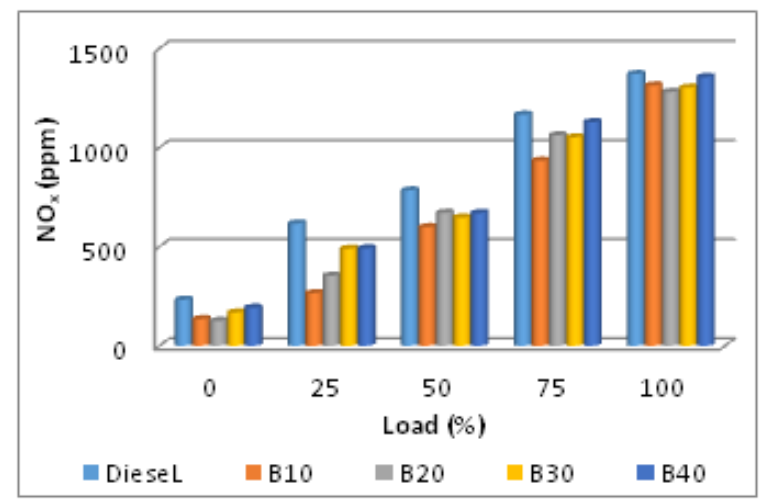

Figure 13: Load Vs Oxides of Nitrogen

\section{E. Exhaust Gas Temperature From Engine}

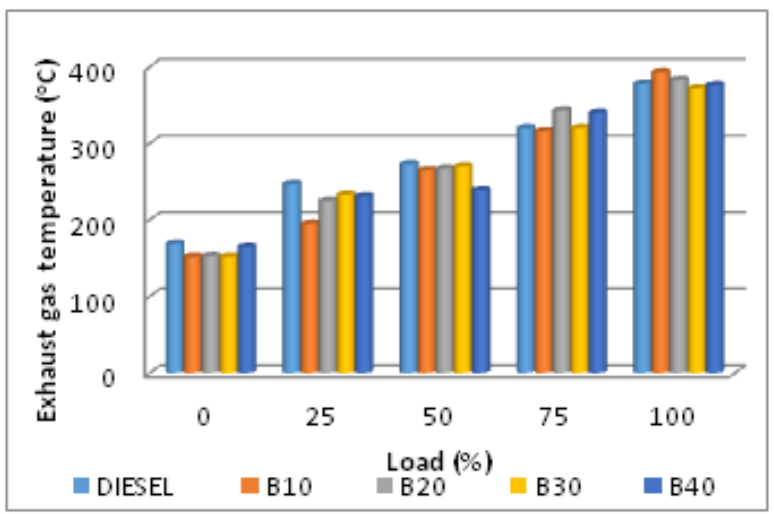

Figure 14: Load Vs Exhaust Gas Temperature

Figure 14 shows the variation of exhaust gas temperature with load for various blends and diesel. The results show that the exhaust gas temperature increases with increase in load for blends. At all loads, diesel and biodiesel are found to have the alternate lowest temperature and the temperatures for various blends show an upward trend with increasing concentration of tamanu oil in the blends. The biodiesel contains oxygen which enables the combustion process and hence the exhaust gas temperatures are higher. Moreover the engine being water cooled runs hotter which resulted in higher exhaust gas temperatures. But, among the blend B30 has the lower exhaust gas temperature than the diesel.

\section{Conclusion}

The following conclusions are drawn from the investigation:

1) The present analysis developed a two stage esterification procedure to produce biodiesel from Tamanu oil.

2) The specific fuel consumption is slightly lower than diesel for B10, B20 but closer to diesel when increase the load.

3) Blends up to $30 \%$ substantially reduce $\mathrm{CO}_{2}$ emissions with a marginal increase in brake thermal efficiency and also it decreases the $\mathrm{HC}$, and $\mathrm{NO}_{\mathrm{x}}$ emissions with increase in load

4) Experimental Investigations show that blending of Tamanu methyl esters up to $30 \%$ (B30) with diesel for use in an unmodified diesel engine is viable and it reduces the harmful emissions

\section{Future Scope}

1) Biodiesel, especially for the blends with a large portion of diesel, is technically feasible as an alternative fuel in CI engines with no modifications to engine. For environmental reasons, their popularity may soon be high.

2) The further improvement in optimization of Tamanu Oil production should be performed in the future to promote its properties and quality. And the further development in additives which improve consumption of biodiesel should be needed to increase performance and reduce emissions.

\section{References}

[1] Penugonda Suresh Babu, Venkata Ramesh Mamilla (2012), "Significance of Biodiesel Use as IC Engine Fuels", International Journals of Advanced Engineering Research and Studies.

[2] Jon Van Gerpen (2005), "Biodiesel processing and production", Fuel Processing Technology 861097-1107.

[3] Barsic, NJ, Humke, AL (1981), "Performance and emission characteristics of a naturally aspirated diesel engine with vegetable oils", Society Automotive Engineering, 1173-1187 paper no. 810262.

[4] B.K.Venkanna, C.Venkataramana Reddy (2009), "Biodiesel production and optimization from Calophyllum inophyllum oil (honne oil) - A three stage method ", Bio resource Technology 100 5122- 5125.

[5] Patil, P.D., Deng, S (2009), "Optimization of bio-diesel production from edible and Non-edible vegetable oils", Fuel 88, 1302-1306.

[6] Ramaraju.A and Ashok Kumar.T.V (2009), "Biodiesel Development from High Free Fatty Acid Punnakka Oil", ARPN Journals of Engineering and Applied Sciences.

[7] Mohan T Raj and Murugumohan Kumar, K Kandasamy (2012), "Tamanu oil - an alternative fuel for variable compression ratio engine", International Journal of energy and Environmental engineering.

[8] Sadasivam.S, Manickam.A, (2004), "Biochemical Methods", second Ed. New Age International (P) Limited, New Delhi, India.

[9] Monyem.A, Gerpen Van, JH (2001), "The effect of biodiesel oxidation on engine performance and emissions". International Journal of Biomass and Bio Energy 20, pp 317-325.

[10] T.Elango, T.Senthilkumar (2011), "Performance and Emission characteristics of CI Engine Fuelled with Non Edible Vegetable oil and Diesel blends", Journal of Engineering Science and Technology Vol. 6, No. 2 240250.

[11] Md. Nurun Nabi, Md. Shamim Akhter, Mhia Md. Zaglul Shahadat (2006), "Improvement of engine emissions with conventional diesel fuel and diesel - biodiesel blends", Bio resource Technology, 97(3), 372-378.

\section{Volume 5 Issue 6, June 2016}

www.ijsr.net 


\section{International Journal of Science and Research (IJSR) \\ ISSN (Online): 2319-7064}

Index Copernicus Value (2013): 6.14 | Impact Factor (2015): 6.391

[12] Nagarhalli M. V, Nandedkar V. M and Mohite K.C (2010), "Emission and performance Characteristics of Karanja Biodiesel and its Blends in a C.I. Engine and its Economics", ARPN Journals of Engineering and Applied Sciences, Vol. 5, No. 2.

[13] Jinlin Xue, Tony E. Grift, Alan C. Hansen (2011), "Effect of Biodiesel on Engine performance and Emissions", Renewable and Sustainable Energy Review 151098 - 1116.

[14] Ayhan Demirbas (2007), "Biodiesel - A realistic fuel for alternative sources", pp 111- 158.

[15]R.D. Misra, M.S. Murthy (2011), "Performance, emission and combustion evaluation of soap nut oildiesel blends in a compression ignition engine", Fuel 90 $2514-2518$.

[16] A.E. Atabani, A.S.Silitonga, H.C.Ong, T.M.I.Mahlia, H.H.Masjuki, Irfan Anjum Badruddin, H.Fayaz (2013), "Non - edible vegetable oils: A critical evaluation of oil extraction, fatty acid composition, biodiesel production, characteristics, engine performance and emissions production", Renewable and Sustainable Energy Review $18211-245$.

[17] V.Ganesan (2007), 'Internal combustion Engines', published by Tata McGraw hill education private limited.

[18] W. Yuan, A. Hansen (2009), 'Computational investigation of the effect of biodiesel fuel properties on diesel engine NOx emissions', Int J Agric \& Biol Eng.

[19] Monyem (1998), "The effect of biodiesel oxidation on engine performance and emissions", Dissertation, Department of Mechanical Engineering, Iowa State University, Ames, IA.

[20]Canakci M (2009), "Combustion characteristics of a turbocharged DI compression ignition engine fuelled with petroleum diesel fuels and biodiesel', Bio-resource Technology; 98 pp 1167-75.

[21] Mustafa Canakci and Jon H. Van Gerpen (2001), "Comparison of Engine Performance and Emissions for Petroleum Diesel Fuel, Yellow Grease Biodiesel, and Soybean Oil Biodiesel", Presented as paper no. 016050, ASAE California, USA.

Volume 5 Issue 6, June 2016 www.ijsr.net 